\title{
Impairment of Select Forms of Spatial Memory and Neurotrophin-Dependent Synaptic Plasticity by Deletion of Glial Aquaporin-4
}

\author{
Vanessa A. Skucas, ${ }^{1}$ Ian B. Mathews, ${ }^{1}$ Jianmin Yang, ${ }^{2}$ Qi Cheng, ${ }^{1}$ Andrew Treister, ${ }^{3}$ Aine M. Duffy, ${ }^{1}$ Alan S. Verkman, ${ }^{4}$ \\ Barbara L. Hempstead, ${ }^{2}$ Marcelo A. Wood, ${ }^{3}$ Devin K. Binder, ${ }^{5}$ and Helen E. Scharfman ${ }^{1,6}$ \\ ${ }^{1}$ The Nathan Kline Institute for Psychiatric Research, Center for Dementia Research, Orangeburg, New York 10962, ${ }^{2}$ Department of Medicine, Division of \\ Hematology/Oncology, Weill Medical College of Cornell University, New York, New York 10065, ${ }^{3}$ Department of Neurobiology and Behavior, University of \\ California at Irvine, Irvine, California 92697, ${ }^{4}$ Departments of Medicine and Physiology, Cardiovascular Research Institute, University of California at San \\ Francisco, San Francisco, California 94143-0521, ${ }^{5}$ Center for Glial-Neuronal Interactions, Division of Biomedical Sciences, University of California at \\ Riverside, Riverside, California 92521, and ' Departments of Child \& Adolescent Psychiatry, Psychiatry, and Physiology \& Neuroscience, New York \\ University Langone Medical Center, New York, New York 10016
}

Aquaporin-4 (AQP4) is the major water channel in the CNS and is primarily expressed in astrocytes. Little is known about the potential for AQP4 to influence synaptic plasticity, although many studies have shown that it regulates the response of the CNS to injury. Therefore, we evaluated long-term potentiation (LTP) and long-term depression (LTD) in AQP4 knock-out (KO) and wild-type mice. KO mice exhibited a selective defect in LTP and LTD without a change in basal transmission or short-term plasticity. Interestingly, the impairment in LTP in KO mice was specific for the type of LTP that depends on the neurotrophin BDNF, which is induced by stimulation at theta rhythm [theta-burst stimulation (TBS)-LTP], but there was no impairment in a form of LTP that is BDNF independent, induced by highfrequency stimulation. LTD was also impaired in KO mice, which was rescued by a scavenger of BDNF or blockade of Trk receptors. TrkB receptors, which mediate effects of BDNF on TBS-LTP, were not altered in K0 mice, but p75NTR, the receptor that binds all neurotrophins and has been implicated in some types of LTD, was decreased. The KO mice also exhibited a cognitive defect, which suggests a new role for AQP4 and astrocytes in normal cognitive function. This defect was evident using a test for location-specific object memory but not Morris water maze or contextual fear conditioning. The results suggest that AQP4 channels in astrocytes play an unanticipated role in neurotrophin-dependent plasticity and influence behavior.

\section{Introduction}

Aquaporin-4 (AQP4) is one of 14 members of the aquaporin (AQP) family, which are membrane proteins that regulate water transport (Verkman, 2008). AQP4 is the primary AQP in the CNS, and is expressed selectively in astrocytes (Nagelhus et al., 2004). Therefore, an AQP4 knock-out (KO) mouse provides an opportunity to investigate the role of fluid regulation by astrocytes.

Using AQP4 KO mice, several studies have demonstrated an important role of AQP4 in the regulation of edema following insults or injury (Papadopoulos and Verkman, 2007). In addition, the extracellular space is altered in AQP4 KO mice (Binder et al., 2004), and AQP4 is colocalized with the potassium chan-

Received Nov. 30, 2010; revised Feb. 26, 2011; accepted March 11, 2011.

Author contributions: J.Y., B.L.H., M.A.W., D.K.B., and H.E.S. designed research; V.A.S., I.B.M., J.Y., Q.C., A.T., A.M.D., and H.E.S. performed research; A.S.V. and B.L.H. contributed unpublished reagents/analytic tools; V.A.S., I.B.M., J.Y., Q.C., A.T., M.A.W., and H.E.S. analyzed data; J.Y., B.L.H., M.A.W., D.K.B., and H.E.S. wrote the paper.

This work was supported by the National Institutes of Health and the New York State Spinal Cord Injury Board. We thank Drs. Philip Haydon, Meyer Jackson, and Eric Klann for comments.

Correspondence should be addressed to Dr. Helen Scharfman, The Nathan Kline Institute for Psychiatric Research, Center for Dementia Research, 140 Old Orangeburg Road, Building 35, Orangeburg, NY 10962. E-mail: hscharfman@nki.rfmh.org.

DOI:10.1523/JNEUROSCI.6249-10.2011

Copyright $\odot 2011$ the authors $\quad 0270-6474 / 11 / 316392-06 \$ 15.00 / 0$ nels Kir4.1 and Kir5.1 (Nagelhus et al., 2004). The effects of AQP4 deletion on excitability appear to be complex, however, because AQP4 KO mice had high seizure thresholds relative to wild-type (WT) mice, but increased seizure duration (Hsu et al., 2007). Furthermore, the functional coupling of AQP4 to Kir4.1 or Kir5.1 has not clearly established a role of AQP4 related to Kir4.1 or Kir5.1 (Zhang and Verkman, 2008; Soe et al., 2009), although the response to a $\mathrm{K}^{+}$challenge is altered in AQP4 KO mice (Binder et al., 2006). Therefore, one would predict that AQP4 would modulate synaptic transmission, but it is hard to predict exactly how.

It seems likely that AQP4 would influence synaptic plasticity [long-term potentiation (LTP), long-term depression (LTD)], because the increased afferent activity that is required for induction of LTP and LTD would be likely to accentuate any effect of AQP4 on basal transmission. Indeed, AQP4 KO mice have a defect in activity-dependent swelling of astrocytes (Kitaura et al., 2009), and there is growing evidence that glia influence synaptic plasticity (Bains and Oliet, 2007; Haydon et al., 2009). Therefore, we tested the hypothesis that AQP4 influences basal synaptic transmission, LTP, and LTD. The Schaffer collateral synapse in area CA1 was evaluated because LTP and LTD are robust in this 
pathway normally. We also evaluated hippocampal-dependent behaviors that would potentially be influenced by LTP or LTD in area $\mathrm{CA1}$, including Morris water maze (MWM), contextual fear conditioning (CFC), and object placement (OP) (Tsien et al., 1996; Ji and Maren, 2008; Assini et al., 2009).

\section{Materials and Methods}

Animal use met National Institutes of Health guidelines. Transgenic mice from Dr. Alan Verkman (CD1 strain) (Ma et al., 1997) were housed with a $12 \mathrm{~h}$ light/dark cycle and fed ad libitum. Chemicals were from Sigma-Aldrich unless otherwise noted. Data are reported as mean \pm SEM with $p<0.05$.

\section{Electrophysiology}

Extracellular recordings. After isoflurane anesthesia, the brain was placed in ice-cold oxygenated $\left(95 \% \mathrm{O}_{2} / 5 \% \mathrm{CO}_{2}\right)$ sucrose-based artificial cerebrospinal fluid (ACSF) (containing, in mM: 126.0 sucrose, $5.0 \mathrm{KCl}, 2.4$ $\mathrm{CaCl}_{2}, 1.0 \mathrm{MgSO}_{4}, 26.0 \mathrm{NaHCO}_{3}, 1.25 \mathrm{NaH}_{2} \mathrm{PO}_{4}, 10.0$ D-glucose), and $400-\mu \mathrm{m}$-thick slices were cut in ice-cold ACSF (Vibroslice; Stoelting). Standard recording procedures were used (see Notes) (Scharfman et al., 2007). All experiments required a stable baseline [field EPSP (fEPSP) slope within $95-105 \%$ of the mean of the first 3 fEPSPs for $15 \mathrm{~min}$ ). For theta-burst stimulation (TBS), 10 trains of 4 half-maximal stimuli at 100 $\mathrm{Hz}$ were triggered $200 \mathrm{~ms}$ apart. For high-frequency stimulation (HFS), 4 trains $(100 \mathrm{~Hz}, 1 \mathrm{~s})$ of half-maximal stimuli were triggered $20 \mathrm{~s}$ apart. Lowfrequency stimulation (LFS) was a $3 \mathrm{~Hz}, 5 \mathrm{~min}$ train of half-maximal stimuli. fEPSPs were normalized to the average of the baseline. LTP or LTD was defined from the average of 3 responses evoked $60 \mathrm{~min}$ after induction. LTP and LTD incidence was defined by $>110 \%$ change (LTP) or $<90 \%$ (LTD). Analysis used pClamp (Molecular Devices) (see Notes).

Whole-cell recording. Slices were warmed $\left(32^{\circ} \mathrm{C}\right)$ in oxygenated sucrose-ACSF ( $1 \mathrm{~h})$, placed in a submerged chamber (model RC-27D; Warner Instruments), and perfused with $\mathrm{NaCl}-\mathrm{ACSF}$ at $2-3 \mathrm{ml} / \mathrm{min}$ at $32^{\circ} \mathrm{C}$ (Inline heater, model TC-324B; Warner Instruments). Recording electrodes used $0.85 \mathrm{~mm}$ inner/1.5 mm outer diameter glass (KG-33; Garner Glass) and were filled with (in $\mathrm{mm}$ ) 90 potassium gluconate, 40 $\mathrm{KCl}, 2 \mathrm{MgCl}_{2}, 10$ EGTA, 10 HEPES, $0.3 \mathrm{Na}_{2} \mathrm{GTP}, 2 \mathrm{Na}_{2} \mathrm{ATP}$, and 1 $\mathrm{Na}_{2}$-phosphocreatine (280-300 mOsm). Recordings were amplified (Axopatch 200B, Molecular Devices), digitized (Digidata 1322A, Molecular Devices), and analyzed using Minianalysis (Synaptosoft). Spontaneous events were confirmed by manual inspection. Membrane potentials were corrected for liquid junction potentials. Cells that changed series resistance $>15 \%$ were discarded.

\section{Behavior}

The MWM used a 119-cm-diameter tub with a white platform hidden 1 $\mathrm{cm}$ below the water surface. The water $\left(20-23^{\circ} \mathrm{C}\right)$ was dyed with nontoxic, white, washable paint to conceal the platform. Black cardboard shapes were placed on room walls for external cues. Mice were handled by a blinded experimenter once per day for $3-5 \mathrm{~d}$ and then trained twice per day (20-30 min interval) for $9 \mathrm{~d}$ with the platform in the same location, and randomly assigned, alternate starting points. Time was measured for the mouse to find the platform, and to stay there for $2 \mathrm{~s}$. The mouse was allowed $60 \mathrm{~s}$ to find the platform, and if it did not, it was placed on the platform, and $60 \mathrm{~s}$ was designated as its time. One day after the $9 \mathrm{~d}$ acquisition phase, mice were subjected to a probe trial to measure retention. The mouse was placed in the water, without the platform, and tracked for $60 \mathrm{~s}$ using video and Ethovision software (v. 3.1; Noldus) to determine the time to reach the platform location during the training phase.

For CFC, conditioning and testing took place in 4 PhenoTyper (Noldus) conditioning chambers as previously described (Pham et al., 2009). OP was tested using standard methods with a 1 or $24 \mathrm{~h}$ interval between the two trials (Scharfman et al., 2007) (see Notes).

\section{Immunoprecipitation and Western blot}

fEPSPs were recorded to confirm that slices were viable $(>5 \mathrm{mV}$ amplitude) for $1-3 \mathrm{~h}$, the time when LTP/LTD was tested, and then frozen in liquid $\mathrm{N}_{2}$. For p75NTR immunoprecipitation (IP)/Western blot, brain slices were lysed (lysis buffer: $1 \times$ Tris-buffered saline, 1\% NP-40, 1\% Triton X-100, 1 mu PMSF, 10\% glycerol, and protease inhibitors) for 30 min on ice. Lysates were further triturated using a 30 ga needle, and supernatants were collected following centrifugation $(14,000 \mathrm{rpm}, 5$ $\mathrm{min})$. Total protein $(1.5 \mathrm{mg}$ ) was immunoprecipitated using biotinylated anti-p75NTR antibodies (\#BAF1157; R\&D Systems) (see Notes). Lysates were pretreated using streptavidin agarose resins (Thermo Fisher Scientific), and the supernatant was incubated with biotinylated anti-p75NTR antibodies overnight at $4^{\circ} \mathrm{C}$. Streptavidin agarose resins were calibrated with lysis buffer and then added to the supernatant $\left(2 \mathrm{~h}, 4^{\circ} \mathrm{C}\right)$ and rotated, and immunoprecipitates were collected ( $5 \mathrm{~min}, 5000 \mathrm{rpm}$ ). Resins were washed in cold lysis buffer $(3 \times 10 \mathrm{~min})$, and immune complexes were resolved by SDS-PAGE. Following transfer, blots were incubated with anti-p75NTR antibodies (1:6000) (Esposito et al., 2001) (see Notes) for $2 \mathrm{~h}$ at room temperature. Blots were developed using horseradish peroxidase-conjugated secondary antibodies and developed with an ECL kit (GE Healthcare Bio-Sciences). For the TrkB Western blot, $60 \mu \mathrm{g}$ of total protein lysates were loaded onto an SDS polyacrylamide gel, and after transfer, the blot was blocked with $5 \%$ skim milk in Tris-buffered saline/Tween 20 overnight at $4^{\circ} \mathrm{C}$. The blot was incubated with anti-TrkB antibodies (1:1500; \#07-225, Millipore) (see Notes), anti- $\beta$-actin (1: 3000; Sigma), and developed as described above. NIH ImageJ software was used for quantification.

\section{Results}

\section{Basal transmission}

Extracellular recordings

WT ( $n=25$ slices, 18 mice) and KO mice ( $n=19$ slices, 15 mice) were age-matched (see Notes). For these experiments and others, 1-2 slices per animal were used. There were no significant differences in the input-output curves (fEPSP slope, amplitude, area, and duration) (see Notes; Fig. $1 A$; two-way repeated-measures ANOVA, $p>0.05$ ) or the maximum fEPSP slope, amplitude, area, total duration, half-duration, or latency to peak (Table 1). There were no differences in the mean amplitude or latency to peak of the fiber volley (Table 1), or the change in fiber volley amplitude with increasing fEPSP slope or amplitude (see Notes). There were no differences in paired-pulse facilitation of fEPSP slope, amplitude, area, or duration (Fig. $1 A$; see Notes).

\section{Whole-cell recordings}

Whole-cell recordings were made from CA1 pyramidal cells using age-matched (see Notes) mice ( $n=7$ per group). Spontaneous PSCs (sPSCs) were recorded at $-90 \mathrm{mV}$ for $3 \mathrm{~min}$, then 0.6 $\mu \mathrm{M}$ tetrodotoxin was added for $15 \mathrm{~min}$, and miniature PSCs (mPSCs) were recorded for $3 \mathrm{~min}$. As shown in Figure $1 \mathrm{~B}$, sPSC and mPSC frequencies were not significantly different (sPSCs, WT: $7.86 \pm 1.39 \mathrm{~Hz}$; KO: $8.18 \pm 0.419 \mathrm{~Hz}$; Student's $t$ test, $p=$ 0.6018; mPSCs, WT: $4.41 \pm 0.75 \mathrm{~Hz}$; KO: $3.98 \pm 1.06 \mathrm{~Hz}$; Student's $t$ test, $p=0.6412$ ), amplitudes were not different (sPSCs, WT: $28.8 \pm 2.6$ pA; KO: $31.0 \pm 2.1 \mathrm{pA}$; Student's $t$ test, $p=$ 0.5331; mPSCs, WT: $14.1 \pm 0.5$ pA; KO: $13.28 \pm 1.4$ pA; Student's $t$ test, $p=0.5757)$, and there were no differences in cumulative probability (Kolmogorov-Smirnov tests, sPSCs, $p=$ 0.1144; mPSCs, $p=0.9670$; Fig. $1 B$ ).

\section{Synaptic plasticity}

\section{TBS-LTP}

Age-matched WT (14 slices, 11 mice) and KO mice (12 slices, 11 mice; see Notes) were used. There were no significant differences in post-tetanic potentiation (PTP), evaluated 1, 2, or 3 min after TBS (Fig. 1C; see Notes). LTP was reduced in magnitude in slices from $\mathrm{KO}$ mice at $60 \mathrm{~min}$ (WT: $134.94 \pm 6.79 \%$; KO: $105.92 \pm$ $8.78 \%$; Student's $t$ test, $p=0.01582$; Fig. $1 C)$. The incidence of 
A 1
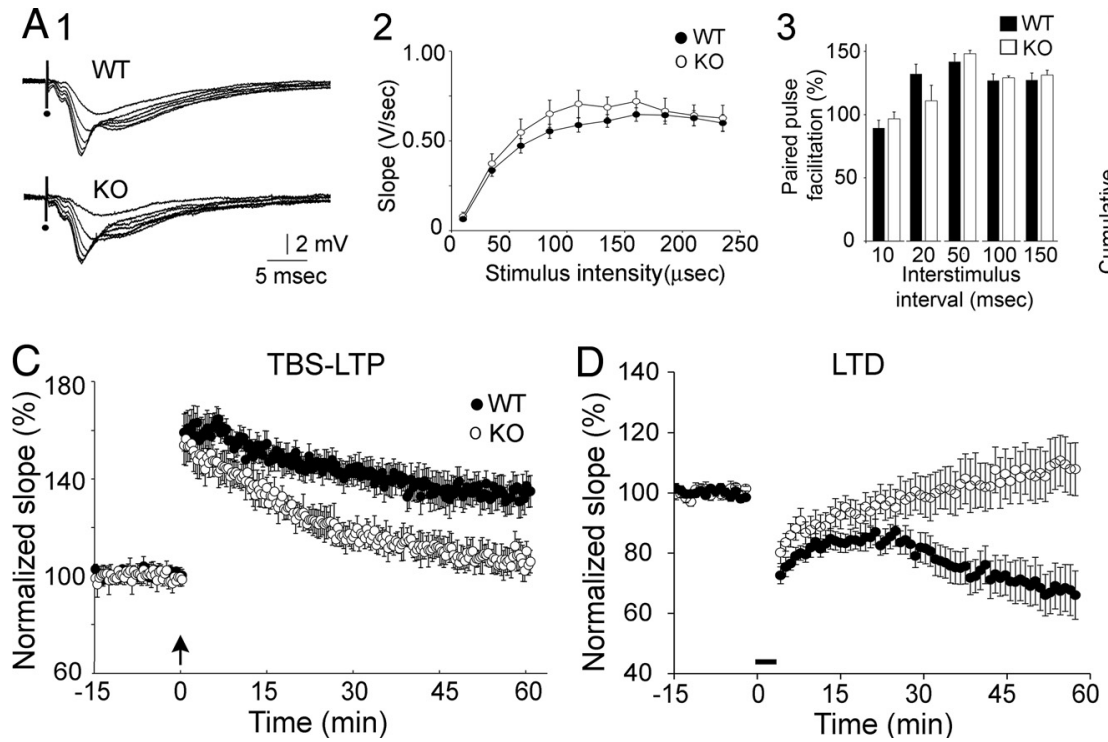
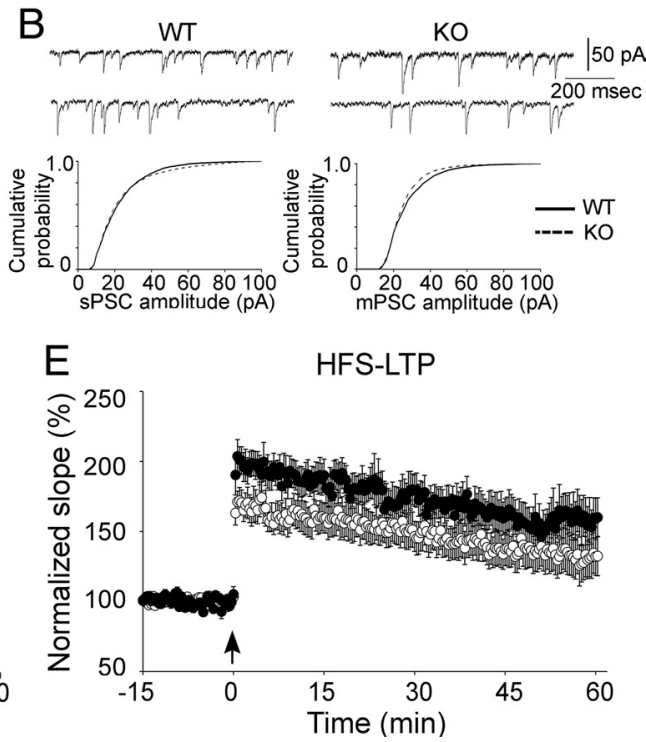

Figure 1. Selective impairments in synaptic plasticity in AQP4 KO mice. A1, Superimposed fEPSPs evoked with increasing stimulus intensities (by increasing the duration of the stimulus, in microseconds) show similar responses in WT and KO mice. A2, Quantified fEPSP slopes show similarity of WT and K0 mice. A3, Similarity of paired-pulse facilitation of fEPSP slope (half-maximal stimuli) in WT and KO mice. B, Top, Similar SPSCs in WT and KO pyramidal cells. Bottom, Cumulative frequency plots did not demonstrate differences in genotypes. C, Comparison of TBS-LTP in WT (black) and KO (white) mice. D, Comparison of LTD in WT and KO mice. E, Comparison of HFS-LTP in WT and KO mice. Arrows denote TBS and HFS; LFS is marked by the bar. Additional data are in the text; also, see Notes.

Table 1. Similarity of fEPSPs in slices of WT and KO mice

\begin{tabular}{|c|c|c|c|c|c|c|c|c|}
\hline & \multicolumn{6}{|l|}{ Field EPSP } & \multicolumn{2}{|l|}{ Volley } \\
\hline & \multirow{2}{*}{$\begin{array}{l}\text { Maximum } \\
\text { slope (V/s) }\end{array}$} & \multirow{2}{*}{$\begin{array}{l}\text { Maximal } \\
\text { amplitude (mV) }\end{array}$} & \multirow{2}{*}{$\begin{array}{l}\text { Area under } \\
\text { the curve (mV*ms) }\end{array}$} & \multirow{2}{*}{$\begin{array}{l}\text { Latency to } \\
\text { peak (ms) }\end{array}$} & \multicolumn{2}{|l|}{ Duration } & \multirow{2}{*}{$\begin{array}{l}\text { Maximal } \\
\text { amplitude (mV) }\end{array}$} & \multirow{2}{*}{$\begin{array}{l}\text { Latency to } \\
\text { peak (ms) }\end{array}$} \\
\hline & & & & & Half-duration (ms) & Total duration (ms) & & \\
\hline Mean & 0.539 & 7.49 & 7.40 & 3.345 & 9.52 & 35.39 & 3.33 & 1.721 \\
\hline SEM & 0.025 & 0.43 & 0.815 & 0.073 & 0.48 & 0.77 & 0.56 & 0.086 \\
\hline$n$ (slices) & 25 & 25 & 25 & 25 & 25 & 25 & 20 & 20 \\
\hline SEM & 0.058 & 0.43 & 0.846 & 0.086 & 0.53 & 1.04 & 0.46 & 0.072 \\
\hline$n$ (slices) & 19 & 19 & 19 & 19 & 19 & 19 & 23 & 23 \\
\hline$p$ & 0.0991 & 0.2653 & 0.6683 & 0.7661 & 0.6662 & 0.2086 & 0.8099 & 0.2319 \\
\hline
\end{tabular}

There were no differences in fEPSPs and fiber volleys in slices from WT and K0 mice.

LTP was lower in KO mice (WT: $85.7 \%$; KO: 50.0\%; $\chi^{2}$ test, $p=$ 0.04918).

Surprisingly, a delayed LTD occurred in KO mice after TBS (Fig. 1C). A possible explanation was that slices from $\mathrm{KO}$ mice were unable to maintain an evoked response, because slices are constantly perfused with an aqueous medium, a possible challenge to a slice that might normally require AQP4 to control water balance. Therefore, additional experiments were conducted in slices of $\mathrm{KO}$ mice to evaluate whether the fEPSPs decayed slowly. There was no significant decay in the fEPSP slope (baseline: $100.13 \pm 1.09 \%$; after 75 min: $98.69 \pm 2.37 \% ; n=6$ slices; paired $t$ test, $p=0.2348$ ). Therefore, TBS evoked LTD in KO mice. To examine LTD further, LFS was used to induce LTD.

\section{LTD}

Age-matched WT (10 slices, 7 mice) and KO mice (12 slices, 10 mice; see Notes) were used. Slices that are used long after the dissection exhibit a form of LTD that is distinct (Dudek and Bear, 1993; Bear, 2003), so slices were used at similar times relative to the slice preparation (WT: $2.57 \pm 0.35 \mathrm{~h}$; KO: $3.08 \pm 0.29 \mathrm{~h}$; Student's $t$ test, $p=0.2658$ ). There were no significant differences in short-term depression (Fig. $1 D$; see Notes), but LTD was re- duced in KO mice (Fig. $1 D$; WT: $66.07 \pm 8.03 \%$; KO: $107.55 \pm$ $8.87 \%$; Student's $t$ test, $p=0.002816)$ and LTD incidence was lower (WT: 80.0\%; KO: 33.3\%; Fisher's exact test, $p=0.02861$ ). Interestingly, a delayed LTP followed LFS in KO mice (Fig. 1D).

\section{HFS-LTP}

Age-matched WT (11 slices, 10 mice) and KO mice (11 slices, 11 mice; see Notes) were used. PTP was not different (Fig. $1 E$; see Notes). As shown in Figure $1 E$, there were no detectable differences in LTP amplitude 60 min after HFS (WT: $155.15 \pm 11.78 \%$; KO: $132.07 \pm 10.50 \%$; Student's $t$ test, $p=0.1617)$ or in incidence (WT: $90.9 \%$; KO: $54.5 \% ; \chi^{2}$ test, $p=0.05551$ ).

\section{Behavior}

Twenty WT and 19 KO litter-matched mice, 12-19 weeks old, were used for MWM testing and 2-3 weeks later for CFC. WT and KO mice exhibited similar performance (Fig. $2 A$ ). Both groups achieved a plateau at approximately day 7 , resulting in average time-to-platform values on day 7 that were not different (WT: $26.98 \pm 5.78 \mathrm{~s} ; \mathrm{KO}: 28.36 \pm 4.63 \mathrm{~s}$; Student's $t$ test, $p=0.8520$ ). No differences were observed in the probe trial: the latency to reach the quadrant where the platform was placed during train- 

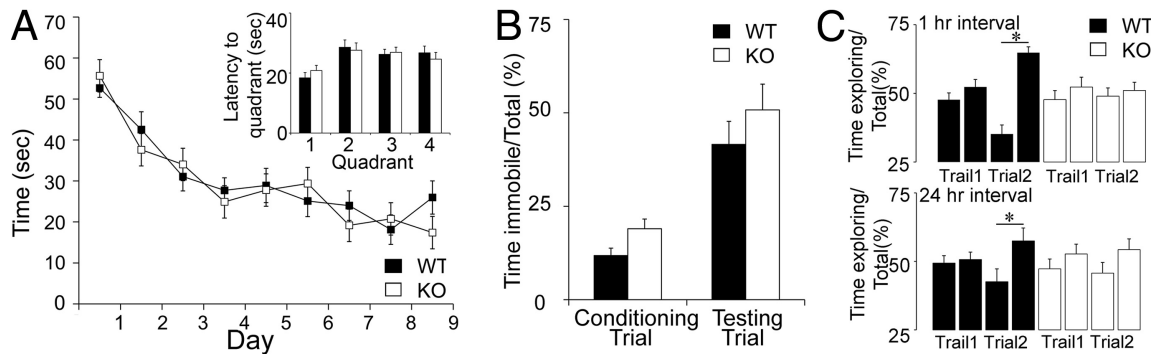

Figure 2. Selective $O P$ deficit in $\mathrm{KO}$ mice. $A$, In the MWM, there were no significant differences in the average time to locate the hidden platform, plotted for each day animals were tested. Inset, There were no differences between genotypes in the probe trial $(1,2,3$, and 4 reflect each quadrant; $4=$ target quadrant; see Notes). Note that CD1 mice normally do not exhibit a preference for the target quadrant in the probe trial (Adams et al., 2002). $\boldsymbol{B}$, In CFC, there were no significant differences between WT and KO mice in the conditioning or testing trials. $C, \mathrm{KO}$ mice were impaired in $\mathrm{OP}$ because they did not spend more time in trial 2 exploring the moved object, but WT mice did.
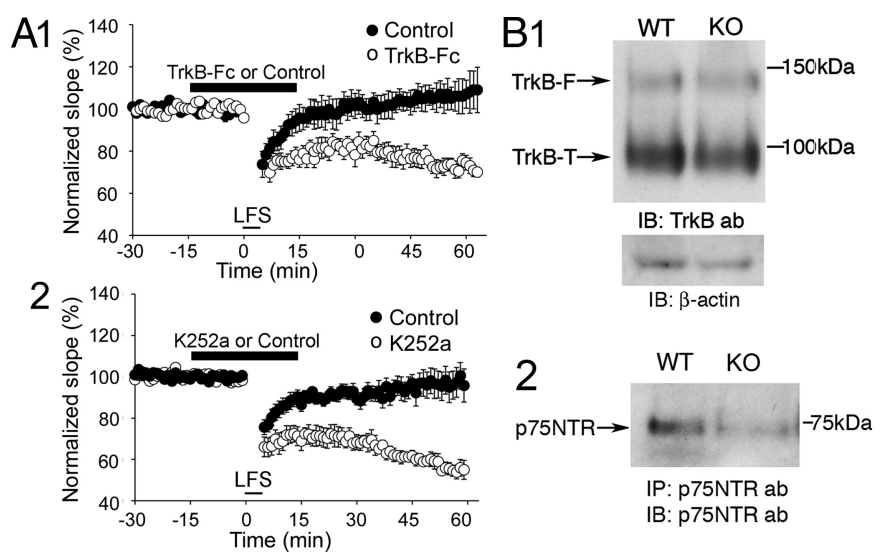

Figure 3. Neurotrophin signaling in WT and KO mice. A1, TrkB-Fc rescued LTD in KO mice. Slices from KO mice were exposed (thick bar) to TrkB-Fc or control lgG for 15 min before and after LFS. A2, K252a rescued LTD in KO mice. Experiments analogous to those in $\boldsymbol{A}$ were conducted, except the slices were exposed to K252a ( $300 \mathrm{~nm})$ or vehicle $(0.05 \%$ DMSO). B1, Full-length (F) and truncated (T) TrkB levels were not significantly different in WT and KO mice. B2, WT mice had reduced p75NTR receptor levels.

ing was $31.38 \pm 5.46 \mathrm{~s}$ for WT and $27.65 \pm 4.50 \mathrm{~s}$ for KO mice (Student's $t$ test, $p=0.5990$; Fig. 2A; see Notes). Swimming speed, tested on the day of the probe trial, was not significantly different (WT: $24.12 \pm 1.15 \mathrm{~cm} / \mathrm{s}$; KO: $26.18 \pm 0.76 \mathrm{~cm} / \mathrm{s}$; Student's $t$ test, $p=0.1304$ ).

When CFC was tested, both genotypes exhibited similar levels of immobility during conditioning (WT: $11.8 \pm 0.02 \%$; KO: $19.0 \pm 0.03 \%$; Student's $t$ test, $p=0.3120$ ), and during the retention test (WT: $41.6 \pm 0.06 \%$; KO: $50.8 \pm 0.07 \%$; Student's $t$ test, $p=0.3170$; Fig. $2 B$ ).

OP was tested in additional mice (WT: $10-16$ weeks old, $n=$ 11; KO: $12-17$ weeks old, $n=10$; Fig. $2 C$ ). WT and KO mice spent the same percentage of time exploring the objects when they were first presented (object 1, WT: $48.69 \pm 1.45 \%$; KO: $48.10 \pm 2.71 \%$; Student's $t$ test, $p=0.8470$; object 2 , WT: $51.31 \pm$ $1.45 \%$; KO: $51.90 \pm 2.71 \%$; Student's $t$ test, $p=0.8470$ ). When mice were retested, WT mice spent more time than KO mice exploring the object that was moved (WT: $64.77 \pm 1.81$; KO: $52.54 \pm 2.21 \%$; Student's $t$ test, $p=0.0003041)$. KO mice did not prefer the moved object (object 2; trial 1:51.90 $\pm 2.71 \%$ vs trial 2: $52.54 \pm 2.21 \%$; paired $t$ test, $p=0.8476$ ), but WT mice did (trial 1: $51.31 \pm 1.45 \%$; trial 2: $64.77 \pm 1.81 \%$; paired $t$ test, $p=$ $0.00006438)$. Similar results were obtained in additional mice (WT, $n=13$; KO, $n=14$ ) when a $24 \mathrm{~h}$ interval was used (Fig. 2C; see Notes). WT mice spent more time exploring the moved object
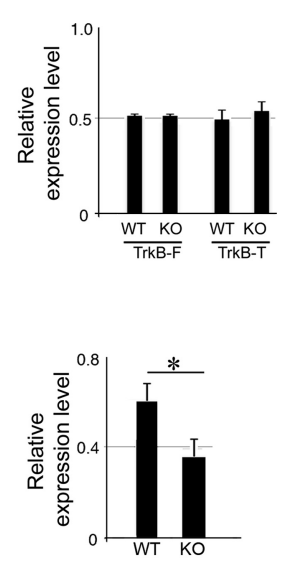

than the stationary object during the test period $(p=0.03559)$, but the KO mice did $\operatorname{not}(p=0.13305)$.

\section{Neurotrophins}

The results suggest that there was a defect in synaptic plasticity in $\mathrm{KO}$ mice that may be related to $\mathrm{BDNF}$ and its TrkB receptor, because maintenance of TBS-LTP requires BDNF and TrkB, whereas HFSLTP does not (Kang et al., 1997; Chen et al., 1999). The LTD impairment in KO mice also suggested a BDNF-associated mechanism, because LFS induced LTP instead of LTD (Fig. 1D; see Notes), and it has been shown that adding BDNF to slices reduces LTD by inducing a superimposed LTP (Akaneya et al., 1996; Aicardi et al., 2004). Therefore, we asked whether scavenging BDNF or interfering with TrkB would rescue LTD. As shown in Figure $3 A 1$, exposure to TrkB-Fc, in concentrations previously shown to scavenge BDNF (Kang et al., 1997), rescued LTD in $\mathrm{KO}$ mice $(\mathrm{KO}+\mathrm{TrkB}-\mathrm{Fc}$, mean slope 60 min after TBS: $71.75 \pm 2.36 \%, n=8$ slices, 8 mice; $\mathrm{KO}+\operatorname{IgG}$ control: 109.01.01 \pm $10.76 \%, n=7$ slices, 7 mice; Student's $t$ test, $p=0.005729)$. K252a (300 nM), a Trk antagonist, also rescued LTD $(\mathrm{KO}+\mathrm{K} 252 \mathrm{a}$, slope $60 \mathrm{~min}$ after TBS: $55.05 \pm 4.560 \%, n=8$ slices, 8 mice; $\mathrm{KO}+0.05 \%$ DMSO control: $95.80 \pm$ $8.003 \%, n=9$ slices, 9 mice; Student's $t$ test, $p=0.001096$; Fig. 3A2).

To determine whether the impairments in LTP and LTD in KO mice were related to receptor levels of TrkB, which is critical to TBS-LTP (Chen et al., 2010), Western blots for TrkB $(n=4)$ and IP/Western blots for p75NTR $(n=4)$ were conducted using slices from age-matched WT ( 38 slices, 11 mice) and $\mathrm{KO}$ mice (51 slices, 12 mice; see Notes). There were no differences in full-length or truncated TrkB between genotypes (Fig. 3B1). However, p75NTR levels were reduced in KO mice (Fig. 3B2; $p=0.0001980$ ).

\section{Discussion}

\section{Summary}

We found that AQP4 KO mice exhibit a defect in TBS-LTP and LTD, without detectable impairments in synaptic transmission and short-term plasticity. Behavior was also impaired in $\mathrm{KO}$ mice, but interestingly, only when a test for location-specific object memory was used.

Our data support an unanticipated role for AQP4 in longterm plasticity and spatial memory. The caveat to this conclusion is the possibility that effects were compensatory to changes induced by deletion of AQP4 during development. Therefore, we cannot rule out the possibility that AQP4 deletion had effects during development that contributed to the results. However, the specificity of impairments in $\mathrm{KO}$ mice make compensation seem unlikely. The results also provide new insight into the mechanisms underlying glial regulation of synaptic plasticity - an unanticipated role of AQP4. Finding a role of glia in regulating 
plasticity that is associated with neurotrophins is also significant because neurotrophins have many important roles in the CNS.

\section{Regulation of neurotrophin-mediated functions by AQP4}

The defect in LTD was rescued by a scavenger of BDNF or an antagonist of Trk receptors, suggesting that the impairment in LTD was caused by excess BDNF released during LFS acting at TrkB to induce LTP, which was superimposed on LTD and therefore reduced LTD, which has been shown in rat cortical slices (Akaneya et al., 1996). However, we cannot rule out other neurotrophin-mediated mechanisms unrelated to BDNF release, such as altered p75NTR, because p75NTR levels were reduced in $\mathrm{KO}$ slices. Also, neurotrophin 3 could be involved because it binds to TrkB.

It is interesting to consider how AQP4 regulates neurotrophindependent plasticity. We suggest that neurotrophins are dysregulated in $\mathrm{KO}$ mice. This hypothesis is based on the evidence that neurotrophin levels during induction are critical to LTP (Chen et al., 1999) and on the results showing that LTD was rescued by pharmacological antagonism of TrkB activation during induction. One reason could be related to the fact that glia normally release neurotrophins, which has been shown in culture (Parpura and Zorec, 2010). Another reason could be due to the low levels of p75NTR in KO mice. This impairment could be important because p75NTR mediates LTD in response to proBDNF (Woo et al., 2005). However, scavenging neurotrophins that bind to TrkB, or blocking Trk, completely rescued LTD, suggesting that reduced p75NTR is not necessary to explain the LTD defect. Nevertheless, reduced p75NTR is significant because of the important functions of p75NTR in the normal developing and adult brain, as well as cell death after injury (Casaccia-Bonnefil et al., 1998; Barker and Kennedy, 2005; Volosin et al., 2008; Angelo et al., 2009). Our data also suggest that AQP4 could be important to the regulation of p75NTR by osmolarity (Ramos et al., 2007).

\section{AQP4 and cognitive function}

When interpreting the LTP, LTD, and behavioral data, it is important to consider that defects in LTP are not always associated with impairment in hippocampal-dependent tasks, such as the MWM (Jun et al., 1998; Leiva et al., 2009), and vice versa (von Engelhardt et al., 2008). In the CD1 mouse strain it is important to note that the probe trial is normally not performed well (Adams et al., 2002). Nevertheless, the behavioral data are interesting, because KO mice were impaired in OP, but not MWM or CFS. It is unlikely that OP was selectively impaired in $\mathrm{KO}$ mice because performance depended on a relatively short interval between training and testing compared with MWM or CFC, because OP was impaired using a $24 \mathrm{~h}$ interval, similar to CFC. Instead, the reason OP was impaired may be due to the fact that different circuitry is required for this task, or the circuitry required for OP depends more on neurotrophins. Indeed, there is support for the idea that OP is BDNF dependent, because of studies using transgenic mice that simulate Alzheimer's disease. Early in life, when BDNF levels decline, there are OP defects (Burghardt et al., 2010) as well as impairment in object recognition (Francis et al., 2010).

\section{Implications}

The results have potential clinical significance because AQP4 regulates edema after injury (Papadopoulos and Verkman, 2007; Kimura et al., 2010). Our data suggest that AQP4 has the potential to regulate not only edema, but also recovery following injury, because BDNF and p75NTR influence the extent of cell death after injury, and BDNF is important to the plasticity that facilitates recovery (Lykissas et al., 2007).

\section{Notes}

Supplemental material for this article (supplemental Methods, four Tables, and four Figures) is available at www.scharfmanlab.com or www.indus3.net/scharfman/supplementalinformation.pdf. This material has not been peer reviewed.

\section{References}

Adams B, Fitch T, Chaney S, Gerlai R (2002) Altered performance characteristics in cognitive tasks: comparison of the albino ICR and CD1 mouse strains. Behav Brain Res 133:351-361.

Aicardi G, Argilli E, Cappello S, Santi S, Riccio M, Thoenen H, Canossa M (2004) Induction of long-term potentiation and depression is reflected by corresponding changes in secretion of endogenous brain-derived neurotrophic factor. Proc Natl Acad Sci U S A 101:15788-15792.

Akaneya Y, Tsumoto T, Hatanaka H (1996) Brain-derived neurotrophic factor blocks long-term depression in rat visual cortex. J Neurophysiol 76:4198-4201.

Angelo MF, Aviles-Reyes RX, Villarreal A, Barker P, Reines AG, Ramos AJ (2009) P75 NTR expression is induced in isolated neurons of the penumbra after ischemia by cortical devascularization. J Neurosci Res 87:1892-1903.

Assini FL, Duzzioni M, Takahashi RN (2009) Object location memory in mice: Pharmacological validation and further evidence of hippocampal CA1 participation. Behav Brain Res 204:206-211.

Bains JS, Oliet SH (2007) Glia: they make your memories stick! Trends Neurosci 30:417-424

Barker P, Kennedy T (2005) Seizure and p75 neurotrophin receptor: death by design? In: Growth factors and epilepsy (Binder DK, Scharfman HE, eds), pp 101-110. New York: Nova Science.

Bear MF (2003) Bidirectional synaptic plasticity: from theory to reality. Philos Trans R Soc Lond B Biol Sci 358:649-655.

Binder DK, Papadopoulos MC, Haggie PM, Verkman AS (2004) In vivo measurement of brain extracellular space diffusion by cortical surface photobleaching. J Neurosci 24:8049-8056.

Binder DK, Yao X, Zador Z, Sick TJ, Verkman AS, Manley GT (2006) Increased seizure duration and slowed potassium kinetics in mice lacking aquaporin-4 water channels. Glia 53:631-636.

Burghardt NS, Bermudez-Herandez KS, Poveda A, Schaner MJ, Duffy AM, Mathews PM, LaFrancois J, Karantzoulis S, DeSanti S, Myers CE, Ferris S, Scharfman HE (2010) Early pathology in entorhinal cortex and dentate gyrus is accompanied by behavioral impairment in a mouse model of Alzheimer's disease. Soc Neurosci Abstr 36:457.28.

Casaccia-Bonnefil P, Kong H, Chao MV (1998) Neurotrophins: the biological paradox of survival factors eliciting apoptosis. Cell Death Differ 5:357-364.

Chen G, Kolbeck R, Barde YA, Bonhoeffer T, Kossel A (1999) Relative contribution of endogenous neurotrophins in hippocampal long-term potentiation. J Neurosci 19:7983-7990.

Chen LY, Rex CS, Sanaiha Y, Lynch G, Gall CM (2010) Learning induces neurotrophin signaling at hippocampal synapses. Proc Natl Acad Sci U S A 107:7030-7035.

Dudek SM, Bear MF (1993) Bidirectional long-term modification of synaptic effectiveness in the adult and immature hippocampus. J Neurosci 13:2910-2918.

Esposito D, Patel P, Stephens RM, Perez P, Chao MV, Kaplan DR, Hempstead BL (2001) The cytoplasmic and transmembrane domains of the p75 and trkA receptors regulate high affinity binding to nerve growth factor. J Biol Chem 276:32687-32695.

Francis BM, Kim J, Barakat ME, Fraenkl S, Yucel YH, Peng S, Michalski B, Fahnestock M, McLaurin J, Mount HT (2010) Object recognition memory and BDNF expression are reduced in young TgCRND8 mice. Neurobiol Aging. Advance online publication. Retrieved November 13, 2010. doi:10.1016/j.neurobiolaging.2010.04.003.

Haydon PG, Blendy J, Moss SJ, Rob Jackson F (2009) Astrocytic control of synaptic transmission and plasticity: a target for drugs of abuse? Neuropharmacology 56 [Suppl 1]:83-90.

Hsu MS, Lee DJ, Binder DK (2007) Potential role of the glial water channel aquaporin-4 in epilepsy. Neuron Glia Biol 3:287-297.

Ji J, Maren S (2008) Differential roles for hippocampal areas CA1 and CA3 
in the contextual encoding and retrieval of extinguished fear. Learn Mem 15:244-251.

Jun K, Choi G, Yang SG, Choi KY, Kim H, Chan GC, Storm DR, Albert C, Mayr GW, Lee CJ, Shin HS (1998) Enhanced hippocampal CA1 LTP but normal spatial learning in inositol 1,4,5-trisphosphate 3-kinase(a)deficient mice. Learn Mem 5:317-330.

Kang H, Welcher AA, Shelton D, Schuman EM (1997) Neurotrophins and time: different roles for trkb signaling in hippocampal long-term potentiation. Neuron 19:653-664.

Kimura A, Hsu M, Seldin M, Verkman AS, Scharfman HE, Binder DK (2010) Protective role of aquaporin- 4 water channels after contusion spinal cord injury. Ann Neurol 67:794-801.

Kitaura H, Tsujita M, Huber VJ, Kakita A, Shibuki K, Sakimura K, Kwee IL, Nakada T (2009) Activity-dependent glial swelling is impaired in aquaporin-4 knockout mice. Neurosci Res 64:208-212.

Leiva J, Palestini M, Infante C, Goldschmidt A, Motles E (2009) Copper suppresses hippocampus LTP in the rat, but does not alter learning or memory in the Morris water maze. Brain Res 1256:69-75.

Lykissas MG, Batistatou AK, Charalabopoulos KA, Beris AE (2007) The role of neurotrophins in axonal growth, guidance and regeneration. Curr Neurovasc Res 4:143-151.

Ma T, Yang B, Gillespie A, Carlson EJ, Epstein CJ, Verkman AS (1997) Generation and phenotype of a transgenic knockout mouse lacking the mercurialinsensitive water channel aquaporin-4. J Clin Invest 100:957-962.

Nagelhus EA, Mathiisen TM, Ottersen OP (2004) Aquaporin-4 in the central nervous system: Cellular and subcellular distribution and coexpression with Kir4.1. Neuroscience 129:905-913.

Papadopoulos MC, Verkman AS (2007) Aquaporin-4 and brain edema. Pediatr Nephrol 22:778-784.

Parpura V, Zorec R (2010) Gliotransmission: exocytotic release from astrocytes. Brain Res Rev 63:83-92.

Pham J, Cabrera SM, Sanchis-Segura C, Wood MA (2009) Automated scor- ing of fear-related behavior using ethovision software. J Neurosci Methods 178:323-326.

Ramos A, Ho WC, Forte S, Dickson K, Boutilier J, Favell K, Barker PA (2007) Hypo-osmolar stress induces p75NTR expression by activating SP1dependent transcription. J Neurosci 27:1498-1506.

Scharfman HE, Hintz TM, Gomez J, Stormes KA, Barouk S, MalthankarPhatak GH, McCloskey DP, Luine VN, Maclusky NJ (2007) Changes in hippocampal function of ovariectomized rats after sequential low doses of estradiol to simulate the preovulatory estrogen surge. Eur J Neurosci 26:2595-2612.

Soe R, Macaulay N, Klaerke DA (2009) Modulation of Kir4.1 and Kir4.1-5.1 channels by small changes in cell volume. Neurosci Lett 457:80-84.

Tsien JZ, Huerta PT, Tonegawa S (1996) The essential role of hippocampal CA1 NMDA receptor-dependent synaptic plasticity in spatial memory. Cell 87:1327-1338.

Verkman AS (2008) Mammalian aquaporins: diverse physiological roles and potential clinical significance. Expert Rev Mol Med 10:e13.

Volosin M, Trotter C, Cragnolini A, Kenchappa RS, Light M, Hempstead BL, Carter BD, Friedman WJ (2008) Induction of proneurotrophins and activation of p75NTR-mediated apoptosis via neurotrophin receptorinteracting factor in hippocampal neurons after seizures. J Neurosci 28:9870-9879.

von Engelhardt J, Doganci B, Jensen V, Hvalby Ø, Göngrich C, Taylor A, Barkus C, Sanderson DJ, Rawlins JN, Seeburg PH, Bannerman DM, Monyer H (2008) Contribution of hippocampal and extra-hippocampal NR2Bcontaining NMDA receptors to performance on spatial learning tasks. Neuron 60:846-860.

Woo NH, Teng HK, Siao CJ, Chiaruttini C, Pang PT, Milner TA, Hempstead BL, Lu B (2005) Activation of p75NTR by proBDNF facilitates hippocampal long-term depression. Nat Neurosci 8:1069-1077.

Zhang H, Verkman AS (2008) Aquaporin-4 independent Kir4.1 $\mathrm{K}^{+}$channel function in brain glial cells. Mol Cell Neurosci 37:1-10. 